\title{
Ambulatory blood pressure response to triple therapy with an angiotensin-receptor blocker (ARB), calcium-channel blocker (CCB), and HCTZ versus dual therapy with an $A R B$ and HCTZ
}

\author{
This article was published in the following Dove Press journal: \\ Vascular Health and Risk Management \\ 23 November 2011 \\ Number of times this article has been viewed
}

\section{Daniel Duprez' \\ Keith Ferdinand ${ }^{2}$ \\ Das Purkayastha ${ }^{3}$ \\ Rita Samuel ${ }^{3}$ \\ Richard Wright ${ }^{4}$}

'University of Minnesota, Minneapolis, MN, ${ }^{2}$ Atlanta Clinical Research Centers, Atlanta, GA, ${ }^{3}$ Novartis Pharmaceuticals Corporation, East Hanover, NJ, ${ }^{4}$ Pacific Heart Institute, Santa Monica, CA, USA
Correspondence: Daniel A Duprez, Cardiovascular Division, University of Minnesota, VCRC - Room 270, 420 Delaware St SE, MMC 508, Minneapolis, MN 55455, USA

$\mathrm{Tel}+\mathrm{I} 6126244948$

Fax +I 61262644 II

Email dupre007@umn.edu
Background: Stage 2 hypertension often requires combination antihypertensive therapy. Ambulatory blood pressure monitoring (ABPM) is a useful tool for assessing antihypertensive drugs and their combinations.

Objective: To compare the effect of a moderate dose of angiotensin receptor blocker/calcium channel blocker $(\mathrm{ARB} / \mathrm{CCB})$ combined with a diuretic versus a maximal dose of ARB with a diuretic on 24-hour ambulatory blood pressure monitoring (ABPM) and other derived ambulatory blood pressure (ABP) parameters.

Methods: The EXforge As compared to Losartan Treatment ABPM substudy was a randomized, double-blind, parallel-group, active-control, forced-titration study of patients with Stage 2 hypertension that compared the efficacy of initial treatment with valsartan/amlodipine $160 / 5 \mathrm{mg}$ $(\mathrm{n}=48)$ or losartan $100 \mathrm{mg}(\mathrm{n}=36)$. At week 3, hydrochlorothiazide (HCTZ) $25 \mathrm{mg}$ was added in both treatment groups. ABP was measured at baseline and at week 6. Additionaly, 24-hour ABP, nighttime (10 pm to $6 \mathrm{am}$ ) and daytime ( 6 am to $10 \mathrm{pm}$ ) ABP, and ABP load (percentage of readings above $140 / 90 \mathrm{mmHg}$ ) were determined.

Results: Eighty-four patients (48 ARB/CCB/HCTZ, $36 \mathrm{ARB} / \mathrm{HCTZ}$ ) had ABPM at baseline and at week 6. Reductions of systolic/diastolic ABP were greater in the ARB/CCB/ HCTZ group than in the ARB/HCTZ group for 24-hour mean ABP (-22.0/-13.3 versus $-17.4 /-8.1 \mathrm{mmHg})$, as well as nighttime $\mathrm{ABP}(-22.2 /-13.3$ versus $-16.2 /-7.4 \mathrm{mmHg})$, daytime ABP $(-21.9 /-13.0$ versus $-18.1 /-8.6 \mathrm{mmHg})$, ABP in the last 4 hours of the dosing period ( $-21.5 /-13.5$ versus $-17.0 /-7.7 \mathrm{mmHg})$, and ABP load (21.7\%/12.8\% versus 30.8\%/20.0\%).

Conclusion: Initiating antihypertensive treatment with moderate doses of ARB/CCB with a diuretic is more effective in lowering nighttime and daytime ABP and reducing ABP load than a maximal dose of an ARB with a diuretic.

Keywords: antihypertensive drugs, ambulatory blood pressure, ambulatory blood pressure monitoring, combination therapy, valsartan, amlodipine, hydrochlorothiazide, losartan

\section{Background}

There is overwhelming evidence that ambulatory blood pressure (ABP) monitoring $(\mathrm{ABPM})$ is better at predicting future risk for cardiovascular morbidity and mortality compared with usual office blood pressure (BP) measurements in both untreated and treated hypertensive patients. ${ }^{1-4}$ The BP load, defined as the percentage of readings in 24-hour ABP in which BP is above $140 / 90 \mathrm{mmHg}$, has also been shown to predict target organ damage in patients with arterial hypertension. ${ }^{5,6}$ ABPM is a useful tool for studying antihypertensive drugs and their combinations and provides greater 
insight into circadian BP variation than does clinic BP monitoring. Other clinically important features of ABPM are its ability to assess the capacity of a given antihypertensive treatment to adequately control BP throughout the 24-hour dosing period, and to provide information on the possible need to differentiate dosing times of different drugs. ${ }^{7,8}$

Among patients with Stage 2 hypertension, the combination of two or more agents is recommended as initial treatment to achieve BP control. ${ }^{9-11}$ Many renin-angiotensin II-aldosterone system (RAAS)-based single-pill combinations include either an angiotensin-converting-enzyme (ACE) inhibitor or an angiotensin receptor blocker (ARB) with a diuretic (eg, hydrochlorothiazide [HCTZ]), or an ACE inhibitor or ARB with a calcium-channel blocker (CCB). RAAS/ Diuretic and RAAS/CCB combinations have fully additive BP-lowering effects. ${ }^{11}$ However, based on findings from the Avoiding Cardiovascular Events through Combination Therapy in Patients Living with Systolic Hypertension study, a RAAS/CCB combination may control BP more effectively and reduce cardiovascular morbidity and mortality, as compared with a RAAS/diuretic combination. ${ }^{12,13}$

The additional $\mathrm{BP}$ reduction that results from combining antihypertensive agents from two different classes is approximately five times greater than would result from doubling the dose of a single antihypertensive agent. ${ }^{14}$ Thus, it was hypothesized that a triple-therapy combination of moderate doses of an ARB and a CCB with a diuretic would be more effective than a dual-therapy combination of the maximal dose of an ARB with a diuretic. Using clinic BP measures, the authors reported in the EXforge As compared to Losartan Treatment (EXALT) study that early initiation of a tripletherapy $\mathrm{ARB} / \mathrm{CCB} / \mathrm{HCTZ}$ combination lowered BP more effectively than a maximal-dose dual-therapy ARB/HCTZ combination in 488 patients with Stage 2 hypertension. ${ }^{15}$ ABP outcomes are reported here for the subgroup of patients from the EXALT study who had ABPM at baseline and after 6 weeks of study treatment.

\section{Methods}

The design of the EXALT study has been reported in full previously. ${ }^{15}$ It was a randomized, double-blind, parallel-group, active-control, forced-titration trial that was conducted between July 2009 and January 2010 at 80 centers in the USA. Twenty centers with capabilities to use the ABP device participated in the ABPM substudy. Ethics committee and/or institutional review board approval was granted at all participating centers, and all patients provided written informed consent before enrollment. The study was conducted in accordance with the ethical principles of the Declaration of Helsinki.

\section{Eligibility criteria}

Male and female outpatients aged $\geq 18$ years were enrolled in the EXALT study if they had Stage 2 systolic hypertension, defined as a mean in-office sitting systolic BP (MSSBP) of $\geq 160 \mathrm{mmHg}$ and $<200 \mathrm{mmHg}$ at randomization. Patients were excluded if they were taking more than three antihypertensive medications at study enrollment or if BP was $\geq 140 / 90 \mathrm{mmHg}$ while on triple therapy (one therapy of which was a diuretic) at the optimal dose of each drug. Other key exclusion criteria were: $\mathrm{MSSBP} \geq 200 \mathrm{mmHg}$ or mean sitting diastolic BP $(\mathrm{MSDBP}) \geq 110 \mathrm{mmHg}$ at the time of enrollment (ie, prior to washout); use of four or more antihypertensive medications in the past 30 days; secondary hypertension; significant heart disease (eg, recent stroke/transient ischemic attack, heart failure, coronary artery bypass graft surgery, coronary intervention, unstable angina, myocardial infarction, heart block, atrial fibrillation/flutter, or valve disease); significant renal or hepatic impairment; or baseline serum sodium $<135 \mathrm{mEq} / \mathrm{L}$, serum potassium $<3.5 \mathrm{mEq} / \mathrm{L}$ or $\geq 5.5 \mathrm{mEq} / \mathrm{L}$, or glycosylated hemoglobin $>9 \%$. Exclusion criteria specific to the ABPM substudy were: arm circumference $>42 \mathrm{~cm}$, employment requiring night-shift work, or a history of sleep apnea.

\section{Study design}

Study treatment schedules for the EXALT study have been presented previously. ${ }^{15}$ Study treatment in the ABPM substudy was force titrated as summarized in Figure 1. After screening and a 1 - to 2-week washout, eligible patients were randomized and initiated treatment with valsartan/ amlodipine 160/5 mg or losartan $100 \mathrm{mg}$. At week 3, HCTZ $25 \mathrm{mg}$ was added in both treatment groups. ABPM was performed for 24 hours before study visits at baseline and at week 6.

Patients were discontinued from the study if they had MSSBP $\geq 200 \mathrm{mmHg}$ or MSDBP $\geq 110 \mathrm{mmHg}$, or if they could not be force titrated to the next dose due to adverse events or hypotension (MSSBP $<100 \mathrm{mmHg}$ or MSDBP $<60 \mathrm{mmHg}$ ). Patients took double-blinded study medication once daily, in the morning. On study visit days, clinic BP measures were obtained before the daily dose of study medication. Patients were not permitted to take other antihypertensive or diuretic treatments during the study.

\section{BP assessments}

Patients enrolled in the EXALT study had clinic BP measurements at each study visit with an automated digital 


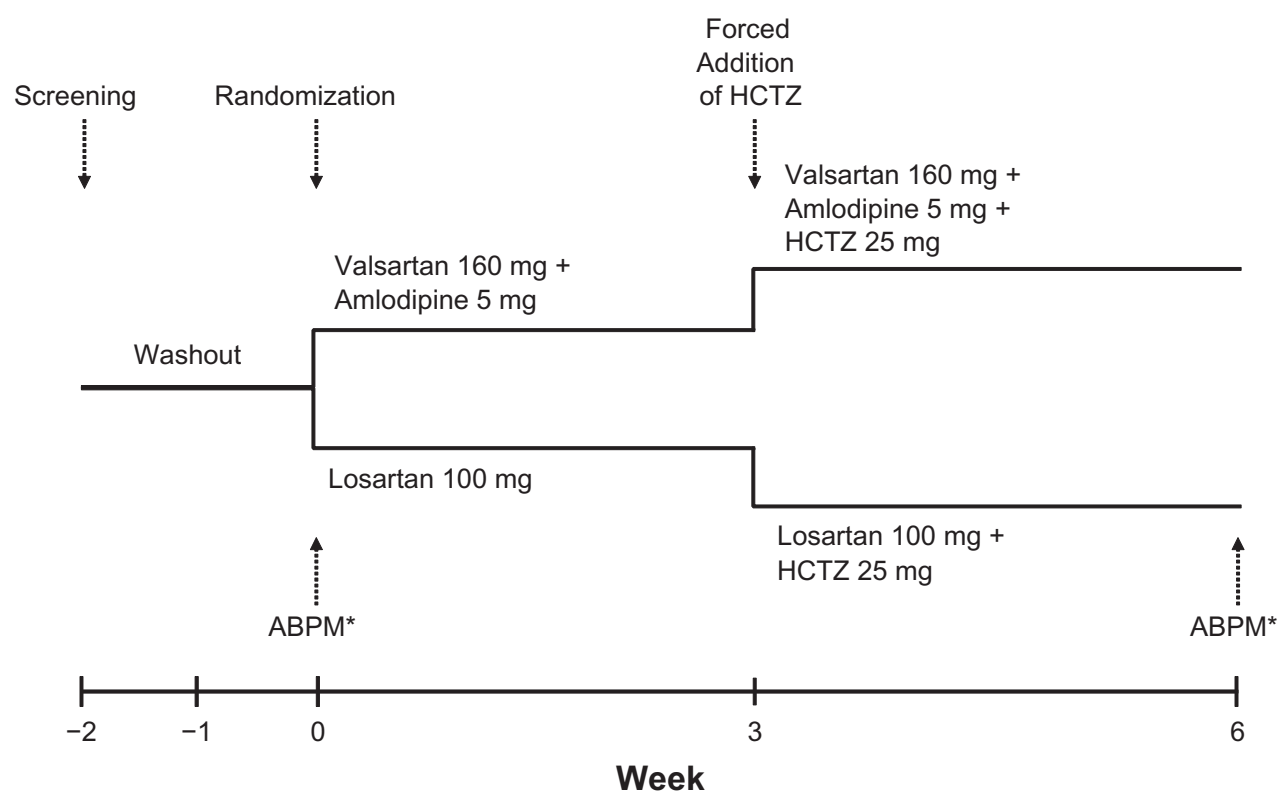

Figure I ABPM substudy design. Study medication was force titrated at week 3 . ABP was measured for 24 hours before the visits at week 0 and week 6 . Note: *ABPM was conducted for 24 hours prior to the week-0 and week-6 visits.

Abbreviations: ABP, ambulatory blood pressure; ABPM, ambulatory blood pressure monitoring; HCTZ, hydrochlorothiazide.

brachial artery BP device; the full methods for clinic BP measurements have been reported previously. ${ }^{15}$ At the 20 centers that participated in the ABPM substudy, patients who expressed interest in participating in the substudy and satisfied the entry criteria were enrolled.

After baseline clinic BP measurement, the ABP device (SpaceLabs 90207, Redmond, WA) was placed on the patient's nondominant arm. Readings were correlated with clinic BP measurements at the time of device placement. Following the correlation procedure, BP and heart rate were recorded every 20 minutes during the 24-hour monitoring period. Qualitycontrol criteria for ABPM were defined as starting between 7 and $10 \mathrm{am}$, with at least 24 hours of ABP data after the beginning of the test time, at least $80 \%$ of expected readings captured during the 24-hour period, and no more than two nonconsecutive hours with no valid BP reading. If baseline $A B P M$ was successful, the patient was randomized into the ABPM substudy. If baseline ABPM was unsuccessful, their randomization was postponed and the $\mathrm{ABP}$ device was reapplied within 48 hours. If the second ABP measurement was successful, the patient was randomized into the study, and ABP was measured again at the week- 6 study visit. Patients who had two unsuccessful attempts to measure mean 24-hour $\mathrm{ABP}$ at baseline were discontinued from the ABPM substudy but were allowed to continue in the main study.

\section{Study endpoints}

The primary study efficacy variable was the change from baseline in MSSBP at week 6 in the overall population, as has been reported previously. ${ }^{15}$ The following efficacy endpoints were evaluated for both systolic and diastolic ABP in this ABPM substudy: 24-hour ABP, nighttime ABP (10 pm to $6 \mathrm{am}$ ), daytime $\mathrm{ABP}$ ( 6 am to $10 \mathrm{pm}), \mathrm{ABP}$ in the last 4 hours of the dosing period, and hourly $\mathrm{ABP}$ values. $\mathrm{ABP}$ load was defined as the percentage of systolic $\mathrm{ABP}$ readings that were $>140 \mathrm{mmHg}$ and the percentage of diastolic ABP readings that were $>90 \mathrm{mmHg}$. Adverse events were recorded at each study visit.

\section{Statistical analysis}

The ABPM substudy population for efficacy and safety analyses in this report included all patients with valid ABPM at baseline and at week 6 . Baseline demographics and clinical characteristics were compared between treatment groups with a two-sample $t$-test for continuous variables and chi-square or Fisher's exact test for categorical variables (excluding missing values). Patients were analyzed for efficacy endpoints according to the treatment they were assigned at randomization. The least-squares mean and standard error of the mean (SEM) for changes in systolic and diastolic ABP from baseline to week 6 were analyzed for 24-hour mean $\mathrm{ABP}$, nighttime $\mathrm{ABP}$, daytime $\mathrm{ABP}$, and $\mathrm{ABP}$ in the last 4 hours of the dosing period. Least-squares mean and SEM for changes in clinic BP measures (MSSBP and MSDBP) from baseline to week 6 were also analyzed for patients participating in the ABPM substudy. Analysis of covariance (ANCOVA) with baseline MSSBP and treatment regimen as explanatory variables was used to 
test each efficacy endpoint for superiority of the valsartan/ amlodipine group over the losartan group. For ABP load, both ANCOVA and a nonparametric Wilcoxon rank-sum test were used to determine between-treatment differences. Adverse events were coded using Medical Dictionary for Regulatory Activities terminology to give a system organ class and preferred term for each event. ${ }^{16}$

\section{Results}

\section{Patients}

Of the 488 patients enrolled in the EXALT study (241 in the valsartan/amlodipine/HCTZ group and 247 in the losartan/ HCTZ group), 416 (85\%) completed the study. ${ }^{15}$ Of the 114 patients who were enrolled in the ABPM substudy, 84 patients (36 in the valsartan/amlodipine/HCTZ group and 48 in the losartan/HCTZ group), satisfied the eligibility criteria and provided valid ABPM data at the baseline visit. All 84 of these patients also completed the follow-up ABP assessment successfully at week 6 . Baseline characteristics among the patients in the ABPM substudy were balanced between treatment groups (Table 1) and were similar to those of the whole study population. ${ }^{15}$

\section{Efficacy ABP}

Baseline values for 24-hour mean $\mathrm{ABP} \pm$ standard deviation $(\mathrm{SD})$ were $150.1 \pm 15.0 / 87.5 \pm 12.0 \mathrm{mmHg}$ and $148.1 \pm 13.8 / 86.1 \pm 11.4 \mathrm{mmHg}$ in the valsartan/amlodipine/ HCTZ and losartan/HCTZ groups, respectively. Least-squares mean \pm SEM reductions in 24-hour mean ABP at week 6 were significantly greater in the valsartan/amlodipine/HCTZ group than in the losar$\tan / \mathrm{HCTZ}$ group $(-22.0 \pm 1.7 /-13.3 \pm 1.0 \mathrm{mmHg}$ and $-17.4 \pm 1.5 /-8.1 \pm 0.8 \mathrm{mmHg}$, respectively; $P=0.043 / P<0.001 ;$ Figure 2). Reductions in nighttime ABP (10 pm to $6 \mathrm{am}$ ), daytime ABP (6 am to $10 \mathrm{pm}$ ), and $\mathrm{ABP}$ in the last 4 hours of the dosing period (the early morning hours prior to the next dose) are shown in Figure 2. At week 6 , significantly greater reduction in systolic ABP was seen for nighttime ABP (10 pm to $6 \mathrm{am}$ ) in the valsartan/amlodipine/ HCTZ group compared with the losartan/HCTZ group.

After 6 weeks of treatment, valsartan/amlodipine/HCTZ provided greater and more consistent reduction of ABP throughout the 24-hour measuring period than losartan/ HCTZ (Figure 3).

Mean values for systolic ABP load (the percentage of readings that were $>140 \mathrm{mmHg}$ ) and diastolic ABP load (the percentage of readings that were $>90 \mathrm{mmHg}$ ) are shown in Figure 4. Reduction of systolic ABP load in the valsartan/ amlodipine/HCTZ group (from $70.2 \%$ to $21.7 \%$ ) was greater than in the losartan/HCTZ group (from $68.3 \%$ to $30.8 \%$; ANCOVA, $P=0.062$; Wilcoxon, $P=0.025$ ). Reduction of diastolic ABP load in the valsartan/amlodipine/HCTZ group (from $42.6 \%$ to $12.8 \%$ ) was also greater than in the losartan/ HCTZ group (from $40.0 \%$ to $20.0 \%$; ANCOVA, $P=0.032$; Wilcoxon, $P=0.053)$.

\section{Clinic BP}

Among the patients in the ABPM substudy population, mean \pm SD baseline values for clinic MSSBP/

Table I Baseline demographics and characteristics by treatment (ABPM substudy population)

\begin{tabular}{|c|c|c|c|}
\hline Variable & Valsartan/Amlodipine/HCTZ group $(n=36)$ & Losartan/HCTZ group $(n=48)$ & $P$-value \\
\hline Age, years, mean $\pm S D$ & $56.1 \pm 8.00$ & $56.0 \pm 8.49$ & 0.940 \\
\hline Sex, male, n (\%) & $17(47.2 \%)$ & $26(54.2 \%)$ & 0.529 \\
\hline Race, n (\%) & & & 0.544 \\
\hline Caucasian & $15(41.7 \%)$ & $26(54.2 \%)$ & \\
\hline Black & $20(55.6 \%)$ & $20(41.7 \%)$ & \\
\hline Asian & $\mathrm{I}(2.8 \%)$ & $\mathrm{I}(2.1 \%)$ & \\
\hline Other & 0 & I (2.I\%) & \\
\hline Diabetes, n (\%) & $8(22.2 \%)$ & $9(18.8 \%)$ & 0.695 \\
\hline Metabolic syndrome, ${ }^{*} \mathrm{n}(\%)$ & $25(69.4 \%)$ & $27(56.3 \%)$ & 0.263 \\
\hline \multicolumn{4}{|l|}{ Clinic $B P, m m H g$, mean $\pm S D$} \\
\hline MSSBP & $168.8 \pm 6.92$ & $170.5 \pm 10.24$ & 0.383 \\
\hline MSDBP & $98.4 \pm 8.59$ & $98.3 \pm 9.02$ & 0.932 \\
\hline \multicolumn{4}{|c|}{ Ambulatory $\mathrm{BP}, \mathrm{mmHg}$, mean $\pm \mathrm{SD}$} \\
\hline Systolic ABP & $150.1 \pm 14.95$ & $148.1 \pm 13.78$ & 0.542 \\
\hline Diastolic ABP & $87.5 \pm 12.01$ & $86.1 \pm 11.44$ & 0.582 \\
\hline
\end{tabular}

Notes: *Defined as central obesity (waist circumference $>40$ inches in non-Asian males, $>35$ inches in Asian males or non-Asian females, $>31$ inches in Asian females) and at least one of the following: fasting plasma glucose $\geq 100 \mathrm{mg} / \mathrm{dL}$; and/or $\mathrm{HDL}<40 \mathrm{mg} / \mathrm{dL}$ for males, $<50 \mathrm{mg} / \mathrm{dL}$ for females; and/or fasting triglycerides $\geq 150 \mathrm{mg} / \mathrm{dL}$. Abbreviations: ABPM, ambulatory blood pressure monitoring; SD, standard deviation; MSSBP, mean sitting systolic blood pressure; MSDBP, mean sitting diastolic blood pressure; $A B P$, ambulatory blood pressure; $\mathrm{HCTZ}$, hydrochlorothiazide. 


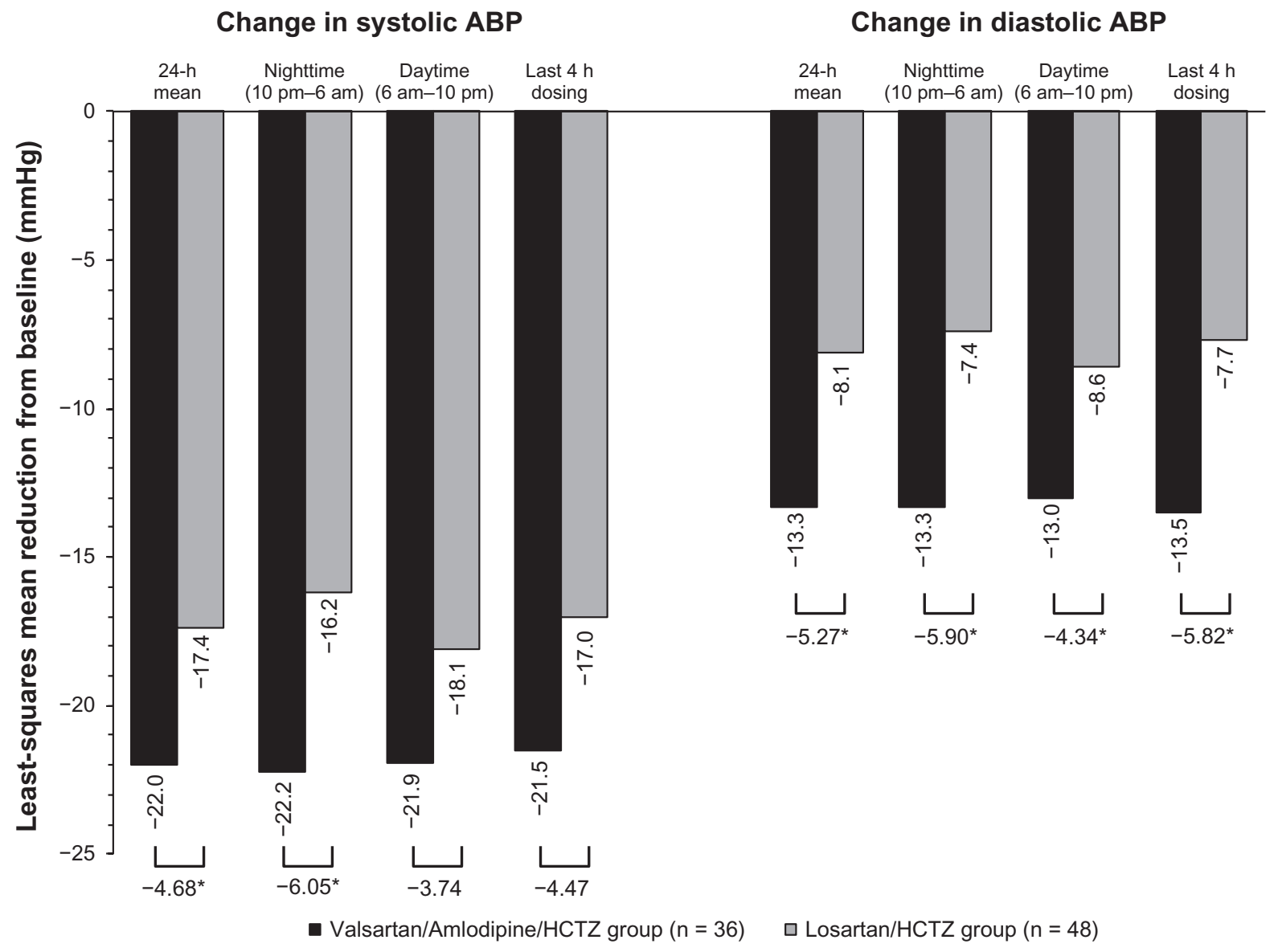

Figure 2 LSM change from baseline to week 6 in ABP. Changes were evaluated for the 24-hour mean values, the average of nighttime values (from 10 pm to 6 am), the average of daytime values (from 6 am to $10 \mathrm{pm}$ ), and the average values during the last 4 hours before the next dose of study medication.

Notes: Least-square mean differences between treatment groups are shown below the bars. $* P<0.05$ by ANCOVA with baseline ABP and treatment regimen as explanatory variables.

Abbreviations: ABP, ambulatory blood pressure; HCTZ, hydrochlorothiazide; ANCOVA, analysis of covariance; LSM, least squares mean.

MSDBP were $168.8 \pm 6.9 / 98.4 \pm 8.6 \mathrm{mmHg}$ and $170.5 \pm 10.2 / 98.3 \pm 9.0 \mathrm{mmHg}$ in the valsartan/amlodipine/ HCTZ group and losartan/HCTZ group, respectively. Least-squares mean \pm SEM reductions of MSSBP/MSDBP at week 6 were $-31.2 \pm 2.8 /-14.3 \pm 1.9 \mathrm{mmHg}$ and $-30.8 \pm 2.4 /-11.0 \pm 1.7 \mathrm{mmHg}$ in the valsartan/amlodipine/ HCTZ group and losartan/HCTZ group, respectively $(P=0.93 / P=0.194)$.

\section{Safety}

Full safety results for the overall population have been reported previously. ${ }^{15}$ In the ABPM substudy population, 12/36 (33\%) patients in the valsartan/amlodipine/HCTZ group and 18/48 (38\%) patients in the losartan/HCTZ group had at least one adverse event by week 6 . The most commonly reported adverse events (valsartan/amlodipine/HCTZ, losartan/HCTZ) were: dizziness (1 [3\%], 3 [6\%]), back pain (2 [6\%], 1 [2\%]), and pain in extremity $(2[6 \%], 0[0 \%])$. One patient in each group had an adverse event of hypotension.

\section{Discussion}

In the EXALT ABPM sub-study, ABP reductions were significantly greater with the valsartan/amlodipine/HCTZ combination than with the losartan/HCTZ combination. These results were consistent with the clinic BP findings of the main study, which was designed to investigate whether triple-combination therapy with moderate doses of an ARB and a CCB with a diuretic was comparable or superior to dual-combination therapy with the maximal available fixed combination dose of an $\mathrm{ARB}$ with a diuretic. ${ }^{15}$ Thus, the observed differences in ABPM lowering were attributable to the combination of moderate doses of a CCB with an ARB + diuretic versus the maximal dose of an $\mathrm{ARB}+$ diuretic.

In contrast to the clinic BP findings of the main study, ${ }^{15}$ among the patients in the ABPM substudy, there was no significant difference in clinic BP results between the two treatment groups. This observation could have been due to the small number of patients in the substudy. For the main 
Systolic ABP (hourly)

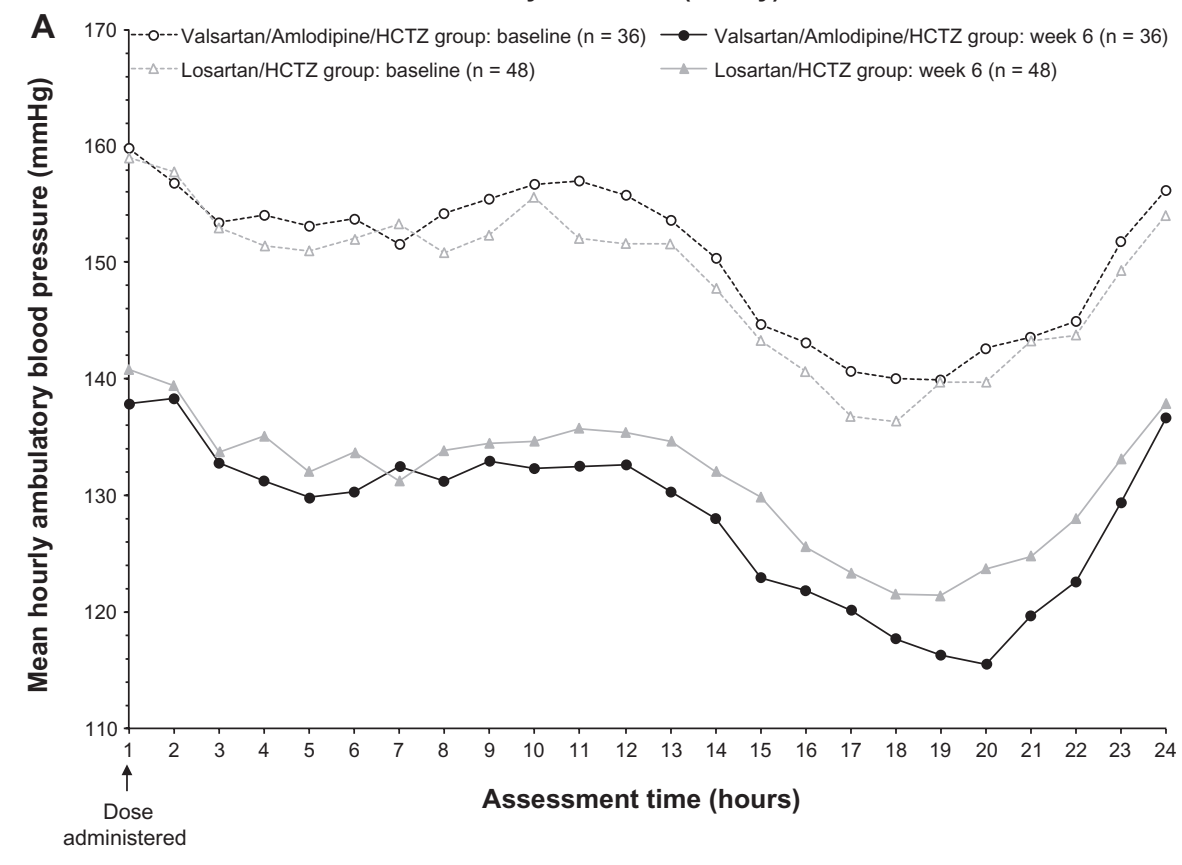

Diastolic ABP (hourly)

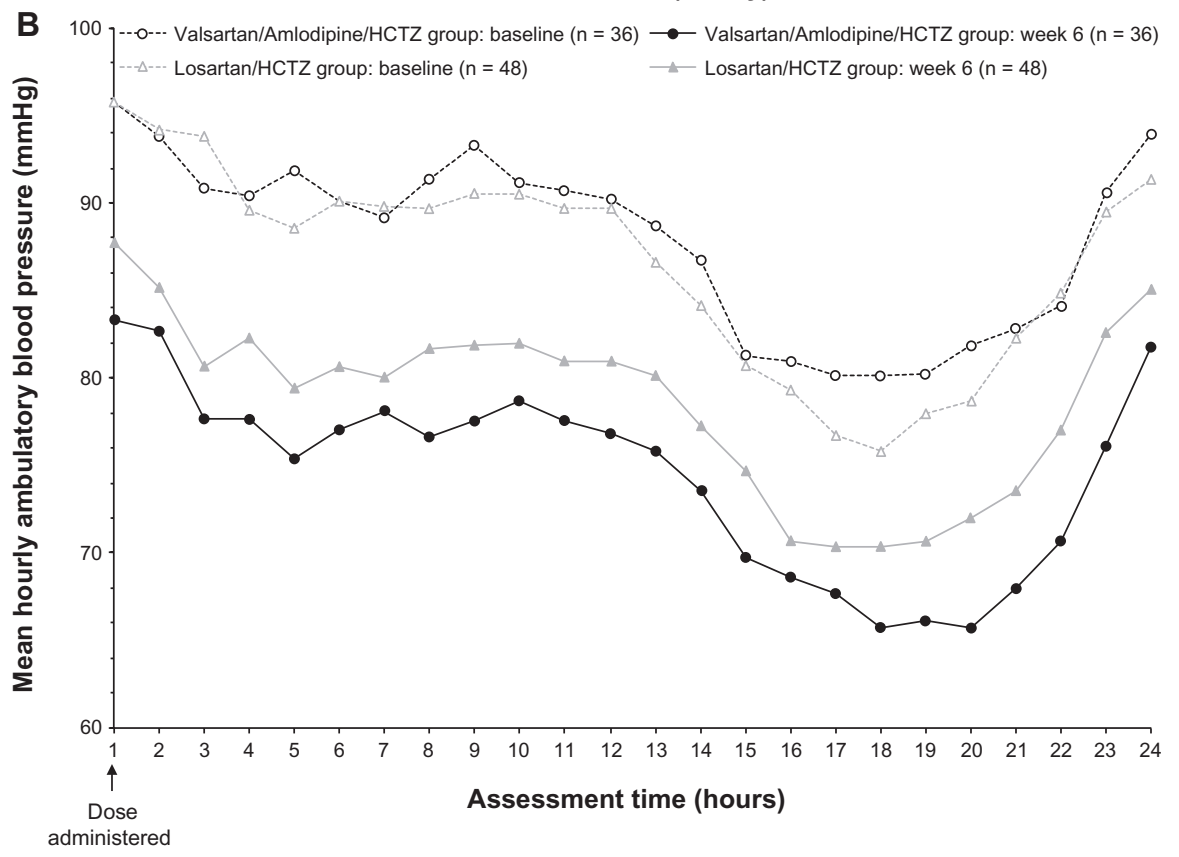

Figure 3 Mean hourly ambulatory blood pressure (ABP) at baseline and at week 6; (A) systolic ABP; (B) diastolic ABP.

Abbreviation: HCTZ, hydrochlorothiazide.

study, a sample size of at least 460 patients was projected to provide adequate power to detect a $5 \mathrm{mmHg}$ difference in clinic BP between treatment groups. Only 84 patients were evaluable in the ABPM substudy; thus, treatment differences using clinic BP measures were not observed. These findings provide additional support for previous evidence that ABPM is a more sensitive measure than clinic BP to evaluate the BP-lowering efficacy of treatment. ${ }^{3}$
In addition to its increased sensitivity for changes in BP control, ABPM can be used to assess the BP-lowering efficacy of a treatment over the entire dosing interval and circadian patterns of BP control. ${ }^{17}$ In this analysis, significant treatment differences were seen not only for 24-hour mean ABP, but also for nighttime ABP (10 pm to $6 \mathrm{am}$ ), and ABP load (percentage of readings $>140 \mathrm{mmHg}$ [systolic] or $>90 \mathrm{mmHg}$ [diastolic]). The differences 


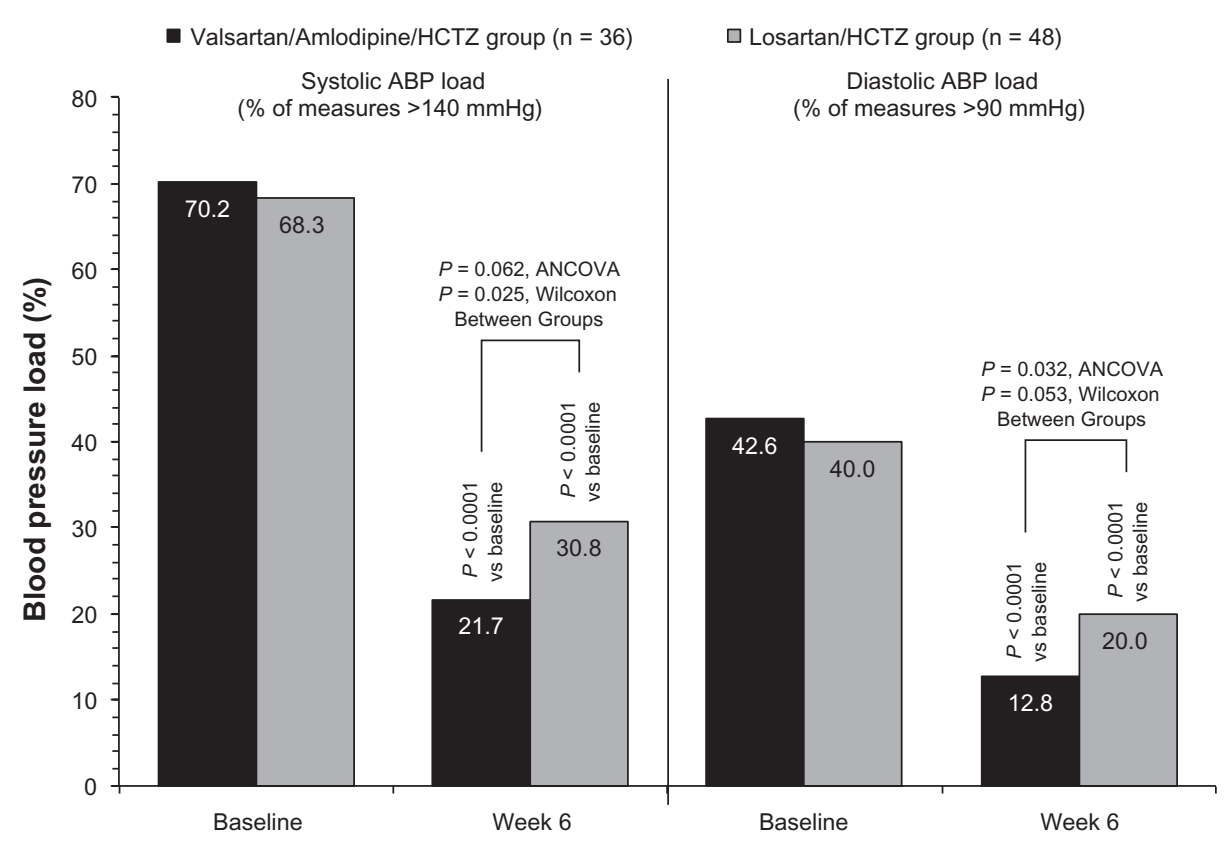

Figure 4 Mean ambulatory blood pressure (ABP) load at baseline and at week 6. Systolic ABP load and diastolic ABP load were defined as the percentage of readings (during the 24-hour ABP monitoring) that were $>140 \mathrm{mmHg}$ and $>90 \mathrm{mmHg}$, respectively.

Abbreviations: HCTZ, hydrochlorothiazide; ANCOVA, analysis of covariance.

between treatment groups in nighttime ABP were more pronounced than the differences in daytime ABP, which shows that triple-therapy combination provides even greater control at nighttime. Diminished nighttime decline in ABP has been shown to predict cardiovascular events ${ }^{18-20}$ and cardiovascular mortality. ${ }^{4,21}$ Similarly, ABP load has been reported to predict end-organ damage in patients with systolic hypertension. ${ }^{5,6}$

Two other recent reports described the effects of triple-therapy or dual-therapy combinations of an ARB, $\mathrm{CCB}$, and diuretic on ABP endpoints in 283 patients $^{22}$ and 380 patients, ${ }^{23}$ respectively. In those studies, the fulldose triple-therapy combinations (valsartan/amlodipine/ HCTZ 320/10/25 mg or olmesartan/amlodipine/HCTZ 40/10/25 mg) lowered 24-hour, nighttime, and daytime ABP significantly more effectively than any dual-therapy combination at the same doses. The authors of the present paper compared lower doses of the ARB and CCB in the triple-therapy combination (valsartan/amlodipine/HCTZ $160 / 5 / 25 \mathrm{mg}$ ) to dual therapy with full-dose losartan with HCTZ (100/25 mg). Although comparing the findings of the present study to the other studies is limited by differences in study populations and study designs, the treatment difference of $5.4 \mathrm{mmHg}$ in favor of the triple-therapy combination for the reduction of 24-hour mean systolic ABP in this study was similar to the $6.4 \mathrm{mmHg}$ difference between the full-dose triple-therapy combinations and the ARB/HCTZ dual-therapy combinations in each of the previous studies. ${ }^{22,23}$

The main limitation of this analysis is the small number of patients in the ABPM substudy. Because of the small sample size, it was not possible to perform subgroup analyses of triple versus dual therapy within different subgroups (eg, gender, age, race, hypertension severity): future studies in these subgroups would be helpful. Another potential limitation is that postbaseline ABP evaluation was done only at week 6 , which provided a single point estimate of the effects of study treatment on ABP.

Despite these limitations, the findings show that using ABPM, initiating treatment with a combination of moderate doses of an ARB, and a CCB with HCTZ lowers BP more effectively than a maximal dose of an ARB with HCTZ. These results support both the efficacy of combining lower doses of multiple antihypertensive agents and the use of $\mathrm{ABP}$ instead of clinic BP as a better measure of treatment efficacy in hypertension.

\section{Acknowledgments}

This work was supported by Novartis Pharmaceuticals Corporation. Dr Duprez provided the outline of the contents and detailed verbal discussion of the manuscript during a meeting held in May 2011. All authors edited the manuscript for scientific intellectual content and approved the final version of the manuscript submitted for publication. The authors 
thank Jonathan Latham of PharmaScribe, LLC, for editorial assistance with support from Novartis Pharmaceuticals Corporation. The authors also thank Katrina Zapotulko of Novartis Pharmaceuticals Corporation for project management support of the clinical trial, the participating investigators for their contributions to the conduct of the study, and study coordinators at the investigative sites for their diligent efforts.

\section{Disclosure}

Dr Duprez has received grant support from Novartis Pharmaceuticals Corporation and Roche, and has served as a consultant to Novartis Pharmaceuticals Corporation and Pfizer Inc. Dr Ferdinand has received research support and honoraria from AstraZeneca Pharmaceuticals LP, Merck and Co, Inc, Novartis Pharmaceuticals Corporation, Pfizer Inc, Forest Labs, and Daiichi Sankyo. Drs Purkayastha and Samuel are employees of and hold stock in Novartis Pharmaceuticals Corporation. Dr Wright has received research support from Novartis Pharmaceuticals Corporation, Atri-tech, and St Jude Medical; honoraria from Novartis Pharmaceuticals Corporation, Boehringer-Ingelheim, Forest Pharmaceutical, and GlaxoSmithKline; and served as a consultant to Novartis Pharmaceuticals Corporation.

\section{References}

1. Conen D, Bamberg F. Noninvasive 24-h ambulatory blood pressure and cardiovascular disease: a systematic review and meta-analysis. J Hypertens. 2008;26:1290-1299.

2. Clement DL, De Buyzere ML, De Bacquer DA, et al. Prognostic value of ambulatory blood-pressure recordings in patients with treated hypertension. N Engl J Med. 2003;348(24):2407-2415.

3. Pickering TG, White WB, Giles TD, et al. When and how to use self (home) and ambulatory blood pressure monitoring. J Am Soc Hypertens. 2010;4(2):56-61.

4. Dolan E, Stanton A, Thijs L, et al. Superiority of ambulatory over clinic blood pressure measurement in predicting mortality: the Dublin outcome study. Hypertension. 2005;46(1):156-161.

5. Falqui V, Viazzi F, Leoncini G, et al. Blood pressure load, vascular permeability and target organ damage in primary hypertension. J Nephrol. 2007;20 Suppl 12:S63-S67.

6. Bauwens F, Duprez D, De Buyzere M, Clement DL. Blood pressure load determines left ventricular mass in essential hypertension. Int J Cardiol. 1992;34(3):335-338.

7. White WB. How well does ambulatory blood pressure predict targetorgan disease and clinical outcome in patients with hypertension? Blood Press Monit. 1999;4 Suppl 2:S17-S21.

Vascular Health and Risk Management

\section{Publish your work in this journal}

Vascular Health and Risk Management is an international, peerreviewed journal of therapeutics and risk management, focusing on concise rapid reporting of clinical studies on the processes involved in the maintenance of vascular health; the monitoring, prevention and treatment of vascular disease and its sequelae; and the involvement of
8. Hermida RC, Ayala DE, Smolensky MH, Portaluppi F. Chronotherapy in hypertensive patients: administration-time dependent effects of treatment on blood pressure regulation. Expert Rev Cardiovasc Ther. 2007; $5(3): 463-475$.

9. White WB. Improving blood pressure control and clinical outcomes through initial use of combination therapy in stage 2 hypertension. Blood Press Monit. 2008;13(2):123-129.

10. Chobanian AV, Bakris GL, Black HR, et al. Seventh report of the joint national committee on prevention, detection, evaluation, and treatment of high blood pressure. Hypertension. 2003;42(6):1206-1252.

11. Gradman AH, Basile JN, Carter BL, Bakris GL. Combination therapy in hypertension. J Am Soc Hypertens. 2010;4(1):42-50.

12. Jamerson K, Bakris GL, Dahlof B, et al. Exceptional early blood pressure control rates: the ACCOMPLISH trial. Blood Press. 2007;16(2): $80-86$.

13. Jamerson K, Weber MA, Bakris GL, et al. Benazepril plus amlodipine or hydrochlorothiazide for hypertension in high-risk patients. $N$ Engl J Med. 2008;359(23):2417-2428.

14. Wald DS, Law M, Morris JK, Bestwick JP, Wald NJ. Combination therapy versus monotherapy in reducing blood pressure: meta-analysis on 11,000 participants from 42 trials. Am J Med. 2009;122(3): 290-300.

15. Wright RF, Duprez D, Purkayastha D, Samuel R, Ferdinand KC. Combination angiotensin-receptor blocker (ARB)/calcium channel blocker with HCTZ vs the maximal recommended dose of an ARB with HCTZ in patients with stage 2 hypertension: the EXforge as compared to Losartan Treatment in Stage 2 systolic hypertension (EXALT) study. J Clin Hypertens (Greenwich). 2011;13(8):588-597.

16. Maintenance and Support Services Organization (MSSO). Medical Dictionary for Regulatory Activities. Chantilly, VA: MSSO; 2011 [updated October 27]. Available from: http:/www.meddramsso.com/. Accessed October 31, 2011

17. Lefebvre J, Poirier L, Lacourciere Y. Methodology to determine duration of action for antihypertensive drugs. Ann Pharmacother. 2002;36(5): 874-881.

18. Staessen JA, Thijs L, Fagard R, et al. Predicting cardiovascular risk using conventional vs ambulatory blood pressure in older patients with systolic hypertension. Systolic hypertension in Europe trial investigators. JAMA. 1999;282(6):539-546.

19. Verdecchia P, Porcellati C, Schillaci G, et al. Ambulatory blood pressure. An independent predictor of prognosis in essential hypertension. Hypertension. 1994;24(6):793-801.

20. Kario K, Pickering TG, Matsuo T, Hoshide S, Schwartz JE, Shimada K. Stroke prognosis and abnormal nocturnal blood pressure falls in older hypertensives. Hypertension. 2001;38(4):852-857.

21. Ohkubo T, Hozawa A, Yamaguchi J, et al. Prognostic significance of the nocturnal decline in blood pressure in individuals with and without high 24-h blood pressure: the Ohasama study. J Hypertens. 2002;20(11): 2183-2189.

22. Lacourcière Y, Crikelair N, Glazer RD, Yen J, Calhoun DA. 24-hour ambulatory blood pressure control with triple-therapy amlodipine, valsartan and hydrochlorothiazide in patients with moderate to severe hypertension. J Hum Hypertens. 2011;25(10):615-622.

23. Izzo J, Melino M, Fernandez V, Lee J, Heyrman R. Twenty-four hour efficacy and safety of full-dose, triple-combination therapy with olmesartan, amlodipine, and hydrochlorothiazide. J Clin Hypertens (Greenwich). 2010;12(Suppl 1):A34-A35.

\section{Dovepress}

metabolic disorders, particularly diabetes. This journal is indexed on PubMed Central and MedLine. The manuscript management system is completely online and includes a very quick and fair peer-review system, which is all easy to use. Visit http://www.dovepress.com/ testimonials.php to read real quotes from published authors. 